\title{
Serial urinary neutrophil gelatinase associated lipocalin in pediatric diabetic ketoacidosis with acute kidney injury
}

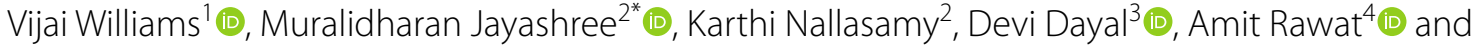
Savita Verma Attri ${ }^{5}$

\begin{abstract}
Background: Acute kidney injury (AKI) due to Diabetic Ketoacidosis (DKA) is rather common. Novel biomarkers to diagnose AKI are being increasingly used in different settings. The use of urinary Neutrophil Gelatinase-Associated Lipocalin (UNGAL) in predicting persistent AKI in pediatric DKA cases is still not thoroughly investigated.

Methods: This was a secondary analysis of Saline versus Plasma-Lyte in Ketoacidosis (SPinK) trial data; 66 children (>1 month-12years) with DKA, defined by the International Society for Pediatric and Adolescent Diabetes (ISPAD), were analyzed. Children with cerebral edema, chronic kidney disease and those who received pre-referral fluids and/ or insulin were excluded. UNGAL and urine NGAL-creatinine ratio (UNCR) at 0 and $24 \mathrm{~h}$ were measured in all. Persistent AKI was defined as a composite outcome of continuance of AKI defined by the Kidney Disease Improving Global Outcomes (KDIGO) stage 2 or 3 beyond $48 \mathrm{~h}$ from AKI onset, progression of AKI from either KDIGO stage 0 or 1 to a worse stage, need of renal replacement therapy or death.
\end{abstract}

Main outcomes: Thirty-five (53\%) children had AKI at admission; 32 (91.4\%) resolved within $48 \mathrm{~h}$. UNGAL was significantly higher in the AKI group at admission [79.8 \pm 27.2 vs $54.6 \pm 22.0, p=0.0002]$ and at $24 \mathrm{~h}[61.4 \pm 28.3$ vs $20.2 \pm 14.5, p=0.0003]$. Similar trend was observed with uNCR at admission [6.7 \pm 3.7 vs $4.1 \pm 2.6, p=0.002]$ and at $24 \mathrm{~h}[6.3 \pm 2.5$ vs $1.2 \pm 1.0, p=0.01]$. Furthermore, UNGAL at admission showed a moderate positive linear correlation with serum creatinine. Additionally, elevated UNGAL at 0 and $24 \mathrm{~h}$ correlated with corresponding KDIGO stages. Admission UNGAL $>88 \mathrm{ng} / \mathrm{ml}$ and $\mathrm{UNCR}$ of $>11.3 \mathrm{ng} / \mathrm{mg}$ had a sensitivity of $66 \%$ and $67 \%$, specificity of $76 \%$ and $95 \%$, and Area under the receiver operating characteristic curve (AUC) of 0.78 and 0.89 respectively for predicting persistent AKI at $48 \mathrm{~h}$

Conclusions: Majority of AKI resolved with fluid therapy. While UNGAL and UNCR both correlated with serum creatinine and AKI stages, serial UNCR was a better predictor of persistent AKI than UNGAL alone. However, feasibility of routine UNGAL measurement to predict persistent AKI in DKA needs further elucidation.

Trial registration: This was a secondary analysis of the data of SPinK trial [CTRI/2018/05/014042 (ctri.nic.in)].

Keywords: Type1 diabetes, Ketoacidosis, Pediatric, Acute kidney injury, Lipocalin

\footnotetext{
*Correspondence: mjshree@hotmail.com

${ }^{2}$ Division of Pediatric Emergency and Intensive Care, Department of Pediatrics, Advanced Pediatrics Centre, Post Graduate Institute of Medical Education \& Research, Chandigarh, India

Full list of author information is available at the end of the article
}

\section{Background}

Diabetic ketoacidosis (DKA) accounts for almost a quarter of all diabetes-related admissions to a hospital $[1,2]$. Several factors, including duration of illness, delayed healthcare seeking, severity of DKA, associated permits use, sharing, adaptation, distribution and reproduction in any medium or format, as long as you give appropriate credit to the original author(s) and the source, provide a link to the Creative Commons licence, and indicate if changes were made. The images or other third party material in this article are included in the article's Creative Commons licence, unless indicated otherwise in a credit line to the material. If material is not included in the article's Creative Commons licence and your intended use is not permitted by statutory regulation or exceeds the permitted use, you will need to obtain permission directly from the copyright holder. To view a copy of this licence, visit http://creativecommons.org/licenses/by/4.0/. The Creative Commons Public Domain Dedication waiver (http://creativeco mmons.org/publicdomain/zero/1.0/) applies to the data made available in this article, unless otherwise stated in a credit line to the data. 
comorbidities, choice of fluid type and volume, and the extent of organ dysfunction determine outcome [3-5]. Among organ dysfunctions, acute kidney injury (AKI) has been reported in about $30-65 \%$ of children with DKA, at the time of presentation [6-9].

AKI in DKA, is largely pre-renal and resolves with adequate hydration [10-12]. However, it can progress to acute tubular injury if acidosis is severe and prolonged, or when DKA is associated with sepsis. Furthermore, compromised renal blood flow and oxidative stress may cascade into endothelial dysfunction, coagulopathy and mitochondrial injury, resulting in intrinsic AKI $[13,14]$. In a few children, AKI can progress to chronic kidney disease (CKD) $[14,15]$. Chen et al. found an association between severity of AKI and risk of rapid progression of CKD in patients hospitalized with DKA [15]. Thus, the development of AKI in DKA has a bearing on both, short-term outcomes like need of renal replacement therapy (RRT), length of hospital stay and mortality, as well as long term outcomes like progression to CKD and increase in cost of care. Early recognition of children in whom AKI is likely to persist may help in prognostication.

AKI may occur in critically ill children in a pediatric intensive care unit (PICU) due to a number of etiologies. From a clinician's perspective, however, it is important to differentiate transient AKI that would respond to fluid therapy, from persistent AKI (as defined by the Sixteenth Consensus Conference of the Acute Dialysis Quality Initiative (ADQI-16) that may require additional renal support. The most widely used marker to detect occurrence and predict persistence of AKI is the rise and persistent elevation of serum creatinine [10, 11]. However, it has a delayed rise after AKI and can be unreliable, as it is often altered by several non-renal factors such as age, body weight, muscle mass, liver dysfunction and protein intake [16]. Similarly, the use of estimated glomerular filtration rate (GFR) as a marker for improvement or worsening of AKI may be imprecise in a setting of dehydration. To address these shortcomings, novel biomarkers are being increasingly used both, for early detection, as well as prediction of non-resolution of AKI.

Urinary neutrophil gelatinase-associated lipocalin (uNGAL) has being studied in different clinical situations as a potential biomarker for early detection of AKI [17]. This $25 \mathrm{kDa}$ protein, that was found first in renal tubules, gets upregulated in epithelial injury due to ischemia [18-20], contrast [21], post cardiac surgery [17, 22, 23] or post-transplantation [24-26]. The utility of serum and urinary NGAL to discriminate transient from persistent AKI, however, is limited to very few studies in critically ill adults $[27,28]$, and the data in critically ill children is scarce [29].
In our setting, children with DKA tend to present late, with greater severity of acidosis and in sepsis or shock; these are all factors that lead to persistent AKI. We hypothesized that serial UNGAL measurements are better than serum creatinine alone in differentiating persistent from transient AKI in children with DKA.

\section{Materials and methods Study design and setting}

This was a secondary analysis of the data collected prospectively during the conduct of Saline versus PlasmaLyte in Ketoacidosis (SPinK) Trial [12]- a single center randomized controlled trial from August 2017 to December 2018 in the Pediatric Emergency and Intensive Care Units of a large tertiary, teaching and referral hospital in India. The objective was to determine the relationship between UNGAL and severity of AKI associated with pediatric DKA and to determine the usefulness of uNGAL in distinguishing transient from persistent AKI.

\section{Definitions}

Acute kidney injury AKI was defined as per Kidney Disease: Improving Global Outcomes (KDIGO) criteria [30]. As pre-admission/ baseline serum creatinine was not available, bedside Schwartz formula was used for its estimation, assuming GFR of $127 \mathrm{~mL} / \mathrm{min}$ for children above 1 year of age and $103 \mathrm{~mL} / \mathrm{min}$ for those below 1 year [11, 31].

Transient AKI Resolution of AKI was defined as the return of serum creatinine from KDIGO stage 2 or 3 (classified as AKI) to either KDIGO stage 0 or 1 (classified as non- AKI) within $48 \mathrm{~h}$ of therapy. The rationale for using this 48-h cut-off was two-fold; firstly, most children recover from AKI within $48 \mathrm{~h}$ and secondly, children who may need additional intervention may be identified early $[11,32,33]$.

Persistent AKI Persistent AKI was defined as a composite outcome of, continuance of AKI (KDIGO stage 2 or 3) beyond $48 \mathrm{~h}$ from AKI onset, progression of AKI from either KDIGO stage 0 or 1 to a worse stage, need of RRT or death.

\section{Participants}

We enrolled all children, aged $>1$ month to $\leq 12$ years, with a diagnosis of DKA, as defined by the International Society for Pediatric and Adolescent Diabetes (ISPAD) $2014(\mathrm{pH}<7.3$, Bicarbonate $<15 \mathrm{mEq} / \mathrm{L}$ and Ketones $>3 \mathrm{mmmol} / \mathrm{l}$ ) [34] presenting to our pediatric Emergency Department (ED). Children with Glasgow Coma Scale 
$(\mathrm{GCS})<8$ at presentation, previously diagnosed chronic kidney disease or liver disease and those who received pre-referral fluids and/or insulin at hospital presentation were excluded. Severity of DKA was classified as mild, moderate and severe if the $\mathrm{pH}$ was between 7.2 and 7.3 , between 7.1 and 7.2 and $<7.1$ respectively as per the ISPAD guidelines.

\section{Treatment protocol and monitoring}

Eligible children, if in shock, received isotonic fluid bolus of $20 \mathrm{ml} / \mathrm{kg}$ over an hour, else the fluid volume was calculated as a sum of deficit $(65-85 \mathrm{ml} / \mathrm{kg})$ and maintenance for the next $48 \mathrm{~h}$ and administered as an hourly infusion. Insulin was started at $0.05 \mathrm{U} / \mathrm{kg} / \mathrm{hour}$ in all, after an initial hour of fluid therapy. Dextrose was added once blood glucose fell below $250 \mathrm{mg} / \mathrm{dl}$. In case of persistent hyperglycemia, the clinician went through a checklist including patency of intravenous access, insulin preparation and its shelf life, and appropriateness of dilution before increasing insulin to $0.1 \mathrm{U} / \mathrm{Kg} /$ hour. The protocol was followed till resolution of DKA defined by $\mathrm{pH}>7.3$, bicarbonate $>15 \mathrm{mEq} / \mathrm{L} \&$ normal sensorium.

\section{Data collection}

Clinical data (respiratory rate, pulse rate, capillary refill time, blood pressure, fluid intake and urine output) were continuously recorded and the values were entered in a pre-designed monitoring sheet. The need for RRT was assessed daily. In addition to renal failure-related data points, the duration of mechanical ventilation (MV), length of ICU and hospital stay, and in hospital mortality were recorded.

\section{Laboratory investigations}

Blood glucose (capillary or venous) was checked hourly, while blood gas analysis was done every $4 \mathrm{~h}$. Urea, creatinine and electrolytes were measured 4-8 hourly for a minimum of $48 \mathrm{~h}$ or until resolution of AKI. Urine samples were collected at admission, concurrent with urinary catheterization and then at $24 \mathrm{~h}$ after the initiation of fluids. Spot uNGAL and corresponding urine creatinine were measured at admission and at $24 \mathrm{~h}$. Spot uNGAL to urine creatinine ratio ( $\mathrm{UNCR}$ ) was obtained by dividing spot UNGAL and corresponding urine creatinine. This was done to mitigate the effect of glomerular filtration on the level of biomarker. All children underwent a urine microscopy and culture and if positive, were excluded from analysis as urinary tract infection (UTI) can erroneously increase UNGAL values.

\section{Test methods}

Urine was centrifuged (at $2000 \mathrm{rpm}$ for $15 \mathrm{~min}$ at room temperature) to remove cellular debris. The clear supernatant was stored at $-80^{\circ} \mathrm{C}$ until measurement. The concentration of uNGAL was estimated with the commercial NGAL ELISA kit (Bio Vendor Human Lipocalin-2/NGAL ELISA), in a sandwich enzyme immunoassay. Limit of NGAL detection was $0.02 \mathrm{ng} / \mathrm{ml}$ with inter-assay $\mathrm{CV}$ of $7.8 \%$ and intra-assay coefficient of variance (CV) of 9.7-9.8\%.

\section{Statistical analysis}

Data is represented as mean with standard deviation or median with inter-quartile range as per normality of distribution. Unpaired Students' t- test or Wilcoxon rank-sum test were used for intergroup comparisons of parametric data and Mann Whitney test or Fischer Exact test for non-parametric data. Unadjusted Chi-Square test was used to analyze the differences in categorical outcome. Patients were divided to two groups viz., AKI and Non-AKI based on their KDIGO staging at admission. The degree of uNGAL elevation was compared with respect to AKI stage at admission and at $24 \mathrm{~h}$. Correlation between UNGAL and creatinine elevation was done. Receiver operating characteristics (ROC) curve was generated and area under curve (AUC) was calculated to assess the discriminatory power of UNGAL to predict persistent AKI at $48 \mathrm{~h}$. The optimal cut off points for sensitivity and specificity were determined by the largest sum of sensitivity and specificity. We compared the absolute urinary biomarker levels (UNGAL and uNCR) at admission along with their respective percentage decline over next $24 \mathrm{~h}$ in predicting persistent AKI at $48 \mathrm{~h}$. A $p$-value ( 2 tailed) $<0.05$ was considered significant in all analyses. Analyses were performed using SPSS software version 23 (IBM SPSS Statistics for Windows, Version 23.0, Armonk, NY, USA).

\section{Results}

Flow of patients

Seventy-seven eligible children were admitted to ED. Eleven were excluded: 8 had received insulin and fluids prior to admission, 2 had cerebral edema and 1 child with mild DKA denied consent. None had chronic kidney disease or liver dysfunction during screening. At the end of screening, 66 children were included in the study. Baseline characteristics of study subjects are as shown in Table 1.

\section{Incidence and determinants of AKI at admission}

At admission, 35 (53\%) children had AKI; 24/35 (68.6\%) in stage 2 and 11/35 (31.4\%) in stage 3. Baseline characteristics of the 2 groups, Non-AKI and AKI (Stage 2 and 3 ), were comparable. The AKI group had higher mean blood glucose, higher osmolality, lower GCS and higher proportion of severe DKA (Table 2). Serum sodium 
Table 1 Baseline characteristics

\begin{tabular}{|c|c|}
\hline Characteristics & $n=66$ \\
\hline Age, years & $7.2 \pm 3.8$ \\
\hline Male gender, n (\%) & $33(50)$ \\
\hline Weight, kg & $19.2 \pm 9.2$ \\
\hline Height, cm & $112.9 \pm 22.3$ \\
\hline Body Mass Index & $14.2 \pm 2.1$ \\
\hline Weight (z score) & $-1.90 \pm 1.68$ \\
\hline Height (z score) & $-1.36 \pm 1.26$ \\
\hline Body Mass Index (z score) & $-1.79 \pm 1.49$ \\
\hline New onset DKA, n (\%) & $41(62.1)$ \\
\hline $\begin{array}{l}\text { Duration of diabetes in prior diagnosed, months, Median } \\
\text { (IQR) }\end{array}$ & $17.4(7.7,39.9)$ \\
\hline Duration of prodromal symptoms, days, Median (IQR) & $5(2,10)$ \\
\hline GCS, Median(IQR) & $13(11,15)$ \\
\hline \multicolumn{2}{|l|}{ Severity of DKA } \\
\hline Mild, $n \%$ & $4(6.1)$ \\
\hline Moderate, n\% & $22(33.3)$ \\
\hline Severe, $n \%$ & $40(60.6)$ \\
\hline \multicolumn{2}{|l|}{ Lab values at presentation } \\
\hline Glucose, mg/dl & $487 \pm 151$ \\
\hline Blood Ketones, mmol/L & $5.5 \pm 0.9$ \\
\hline $\mathrm{pH}$ & $7.02 \pm 0.15$ \\
\hline Sodium, mmol/L & $137.7 \pm 6.9$ \\
\hline Corrected sodium, mmol/L & $143.5 \pm 6.91$ \\
\hline Chloride, $\mathrm{mmol} / \mathrm{L}$ & $111.8 \pm 8.87$ \\
\hline Potassium, mmol/L & $4.02 \pm 0.89$ \\
\hline Urea, mg/dl & $47.2 \pm 39.5$ \\
\hline Creatinine, mg/dl & $0.84 \pm 0.43$ \\
\hline Anion gap, mmol/L & $19.9 \pm 5.1$ \\
\hline Osmolality, mmol/kg & $301.2 \pm 15.1$ \\
\hline Lactate, $\mathrm{mmol} / \mathrm{L}$ & $2.06 \pm 0.88$ \\
\hline Phosphate, mmol/L & $2.7 \pm 0.98$ \\
\hline Hemoglobin, g/dl & $11.5 \pm 2.0$ \\
\hline $\mathrm{HbA}_{1 \mathrm{C}} \%$ & $12.5 \pm 2.4$ \\
\hline
\end{tabular}

† All values expressed as Mean \pm Standard deviation

(absolute and corrected for glucose), chloride and phosphate levels were similar. However, there were no differences between groups in time to endpoint of DKA and duration of PICU or hospital stay.

\section{Relationship between UNGAL and severity of AKI}

The UNGAL at admission and $24 \mathrm{~h}$ was significantly higher in the AKI group $[79.8 \pm 27.2$ vs. $54.6 \pm 22.0$, $p=0.0002]$ and [61.4 \pm 28.3 vs. $20.2 \pm 14.5, p=0.0003$ ] respectively (Table 2). Similarly, uNCR was significantly higher in the AKI group, both at admission [6.7 \pm 3.7 vs. $4.1 \pm 2.6, p=0.002]$ and $24 \mathrm{~h}[6.3 \pm 2.5$ vs. $1.2 \pm 1.0$, $p=0.01]$. The elevation of uNGAL and UNCR at admission and $24 \mathrm{~h}$ were proportionate to the KDIGO staging at admission and $24 \mathrm{~h}$ respectively (Fig. 1 and Table 3). Although the absolute value of uNGAL at $24 \mathrm{~h}$ decreased with fluid therapy, it was commensurate with severity of AKI stage (Table 3). Meanwhile, uNGAL and uNCR showed a moderate positive linear correlation with serum creatinine; Pearson correlation coefficient of 0.61 and 0.54 respectively (Fig. 1 ). The percentage decline in uNGAL from admission to $24 \mathrm{~h}$ of fluid replacement was significantly lower in AKI compared to Non-AKI group $[21.5 \pm 17.0$ vs. $66.8 \pm 21.7, p=0.0003]$. Similarly, the percentage decline of uNCR also was lower in AKI group $[59.8 \pm 38.4$ vs. $74.7 \pm 16.08, p=0.04]$.

\section{UNGAL and prediction of persistent AKI}

Of the 35 children with AKI at admission, resolution was seen in $29(83 \%)$ at $24 \mathrm{~h}$ and $32(91.4 \%)$ at $48 \mathrm{~h}$ following fluid correction (Additional File 1). Receiver operating characteristics (ROC) curves plotted for predictors of persistent AKI at $48 \mathrm{~h}$ are shown in Fig. 2. The sensitivity, specificity and AUC [95\% Confidence Interval (CI)] of UNGAL and UNCR that were measured at admission to predict persistent AKI after $48 \mathrm{~h}$ are shown in Table 3. uNGAL $>88 \mathrm{ng} / \mathrm{ml}$ at admission had a sensitivity of $66 \%$ and specificity of $76 \%$ (PPV-11.8\%, NPV-98\%) while uNCR of $>11.3 \mathrm{ng} / \mathrm{mg}$ at admission, had $67 \%$ sensitivity and 95\% specificity (PPV-40\%, NPV-98\%) in predicting persistent AKI at $48 \mathrm{~h}$ with AUC of 0.78 and 0.89 respectively.

Percentage decline in uNGAL and uNCR had better AUC than absolute UNGAL and UNCR values with an AUC of 0.97 and 0.98 respectively in predicting persistent AKI at $48 \mathrm{~h}$ (Table 3). Percentage decline in uNCR fared better than uNGAL with $\mathrm{a}<50 \%$ fall of uNCR showing $100 \%$ sensitivity and $93 \%$ specificity, while $<50 \%$ fall of uNGAL from baseline showing an 100\% sensitivity and $82 \%$ specificity in predicting AKI.

\section{Outcome after $\mathbf{2 8}$ days follow up}

Of 3 children with persistent AKI at $48 \mathrm{~h}$, one improved during hospital stay and 2 (3\%) died; one child succumbed to fungal sepsis, shock and multi organ dysfunction at $72 \mathrm{~h}$ and other to progressive MODS at $56 \mathrm{~h}$ of PICU stay. At 28-days follow up, all survivors had complete resolution of AKI.

\section{Discussion}

Our study, which is novel in children with DKA, gives preliminary evidence on utility of uNGAL in AKI. AKI was present in more than half of our cohort at the time of admission with DKA; the majority (91.4\%) were transient and resolved with fluids within $48 \mathrm{~h}$. Persistent AKI was seen in a very few children. We found that uNGAL and $\mathrm{UNCR}$ elevations corresponded to AKI stage. While 
Table 2 Comparison of AKI and Non AKI groups at admission

\begin{tabular}{|c|c|c|c|c|}
\hline Parameters & Total $(n=66)$ & AKI $(n=35)$ & Non AKI $(n=31)$ & $\mathbf{P}$ \\
\hline \multicolumn{5}{|l|}{ Baseline Characteristics } \\
\hline Age, years & $7.2 \pm 3.8$ & $6.9 \pm 4.0$ & $7.5 \pm 3.8$ & 0.53 \\
\hline Male gender, $\mathrm{n}(\%)$ & $33(50)$ & $16(45.7)$ & $17(54.8)$ & 0.46 \\
\hline $\mathrm{BMI}$ & $14.2 \pm 2.1$ & $14.1 \pm 2.2$ & $14.3 \pm 2.1$ & 0.75 \\
\hline New onset DKA, n(\%) & $41(62.1)$ & $23(65.7)$ & $18(58.1)$ & 0.06 \\
\hline Duration of diabetes, months, Median (IQR) & $17(8,40)$ & $30(8,45)$ & $17(8,33)$ & 0.62 \\
\hline Duration of prodrome, days, Median (IQR) & $5(2,10)$ & $3(2,7)$ & $7(4,10)$ & 0.09 \\
\hline GCS, Median $(\mathrm{IQR})$ & $13(11,15)$ & $12(10,14)$ & $15(12,15)$ & 0.005 \\
\hline \multicolumn{5}{|l|}{ Severity of DKA } \\
\hline Mild and moderate, n(\%) & $26(39.4)$ & $7(20)$ & $19(61.3)$ & 0.001 \\
\hline Severe, $\mathrm{n}(\%)$ & $40(60.6)$ & $28(80)$ & $12(38.7)$ & \\
\hline \multicolumn{5}{|l|}{ Lab values at presentation } \\
\hline Glucose at $0 \mathrm{~h}, \mathrm{mg} / \mathrm{dl}$ & $487 \pm 151$ & $523 \pm 156$ & $445 \pm 135$ & 0.07 \\
\hline Glucose at $1 \mathrm{~h}, \mathrm{mg} / \mathrm{dl}$ & $447 \pm 151$ & $476 \pm 146$ & $415 \pm 106$ & 0.09 \\
\hline Blood Ketones, mmol/L & $5.5 \pm 1.0$ & $5.4 \pm 0.9$ & $5.6 \pm 1.0$ & 0.20 \\
\hline $\mathrm{pH}$ & $7.02 \pm 0.15$ & $6.97 \pm 0.12$ & $7.08 \pm 0.15$ & 0.002 \\
\hline Bicarbonate, mmol/L & $7.4 \pm 2.5$ & $6.9 \pm 2.4$ & $7.8 \pm 2.5$ & 0.06 \\
\hline Sodium, mmol/L & $138 \pm 6.9$ & $139 \pm 7.6$ & $136 \pm 6.1$ & 0.33 \\
\hline Corrected sodium, mmol/L & $144 \pm 6.9$ & $145 \pm 7.7$ & $142 \pm 5.5$ & 0.08 \\
\hline Chloride, $\mathrm{mmol} / \mathrm{L}$ & $112 \pm 8.8$ & $112 \pm 10.5$ & $111 \pm 7.1$ & 0.87 \\
\hline Potassium, mmol/L & $4.0 \pm 0.89$ & $4.3 \pm 0.9$ & $3.7 \pm 0.7$ & 0.02 \\
\hline Anion gap, mmol/L & $19.9 \pm 5.1$ & $20.4 \pm 5.3$ & $19.4 \pm 5.0$ & 0.51 \\
\hline Osmolality, mmol/kg & $301 \pm 15$ & $306 \pm 16$ & $295 \pm 12$ & 0.0001 \\
\hline Phosphate, mmol/L & $2.7 \pm 0.98$ & $2.7 \pm 0.9$ & $2.7 \pm 1.1$ & 0.84 \\
\hline $\mathrm{HbA}_{1 \mathrm{C}} \%$ & $12.5 \pm 2.4$ & $12.6 \pm 2.5$ & $12.3 \pm 2.6$ & 0.63 \\
\hline \multicolumn{5}{|l|}{ Fluid therapy } \\
\hline Fluids received, ml/kg [Median (IQR)] & $66(46,100)$ & $80(55,103)$ & $58(37,93)$ & 0.04 \\
\hline Urine output, $\mathrm{ml} / \mathrm{kg} / \mathrm{hr}$ & $2.9(2.2,3.5)$ & $2.7(2.0,3.5)$ & $3.0(2.5,3.8)$ & 0.54 \\
\hline \multicolumn{5}{|l|}{ Creatinine, mg/dl } \\
\hline $\mathrm{Oh}$ & $0.85 \pm 0.43$ & $1.1 \pm 0.41$ & $0.55 \pm 0.17$ & $<0.0001$ \\
\hline $24 \mathrm{~h}$ & $0.56 \pm 0.44$ & $0.68 \pm 0.57$ & $0.42 \pm 0.14$ & 0.002 \\
\hline $48 \mathrm{~h}$ & $0.49 \pm 0.44$ & $0.6 \pm 0.5$ & $0.35 \pm 0.11$ & 0.001 \\
\hline \multicolumn{5}{|l|}{ uNGAL, ng/ml } \\
\hline $\mathrm{Oh}$ & $67.8 \pm 27.7$ & $79.8 \pm 27.2$ & $54.6 \pm 22.0$ & 0.0002 \\
\hline $24 \mathrm{~h}$ & $24.2 \pm 20.2$ & $61.4 \pm 28.3$ & $20.2 \pm 14.5$ & 0.0003 \\
\hline Decline over $24 \mathrm{~h}(\%)$ & $62.3 \pm 25.9$ & $21.5 \pm 17.0$ & $66.8 \pm 21.7$ & 0.0003 \\
\hline \multicolumn{5}{|l|}{ uNCR, ng/mg } \\
\hline $\mathrm{Oh}$ & $5.4 \pm 3.4$ & $6.7 \pm 3.7$ & $4.1 \pm 2.6$ & 0.002 \\
\hline $24 \mathrm{~h}$ & $2.8 \pm 1.7$ & $6.3 \pm 2.5$ & $1.2 \pm 1.0$ & 0.01 \\
\hline Decline over $24 \mathrm{~h}(\%)$ & $71.0 \pm 25.5$ & $59.8 \pm 38.4$ & $74.7 \pm 16.08$ & 0.04 \\
\hline \multicolumn{5}{|l|}{ Outcome } \\
\hline Duration to achieve end points, hours & $15.0 \pm 7.1$ & $16.4 \pm 7.1$ & $13.6 \pm 7.0$ & 0.11 \\
\hline Length of PICU stay, hours & $48 \pm 21$ & $52 \pm 24$ & $42 \pm 17$ & 0.17 \\
\hline Length of Hospital stay, days & $10 \pm 4.6$ & $10 \pm 4.8$ & $10 \pm 4.4$ & 0.93 \\
\hline
\end{tabular}

†All values expressed as Mean \pm Standard deviation

both were good predictors of persistent AKI, uNCR performed better than UNGAL. Serial decrease in levels over time was more prognostic than spot values.
Over the last two decades, as the understanding of AKI has evolved, the emphasis has shifted from early detection of AKI to early prediction and pattern of recovery 

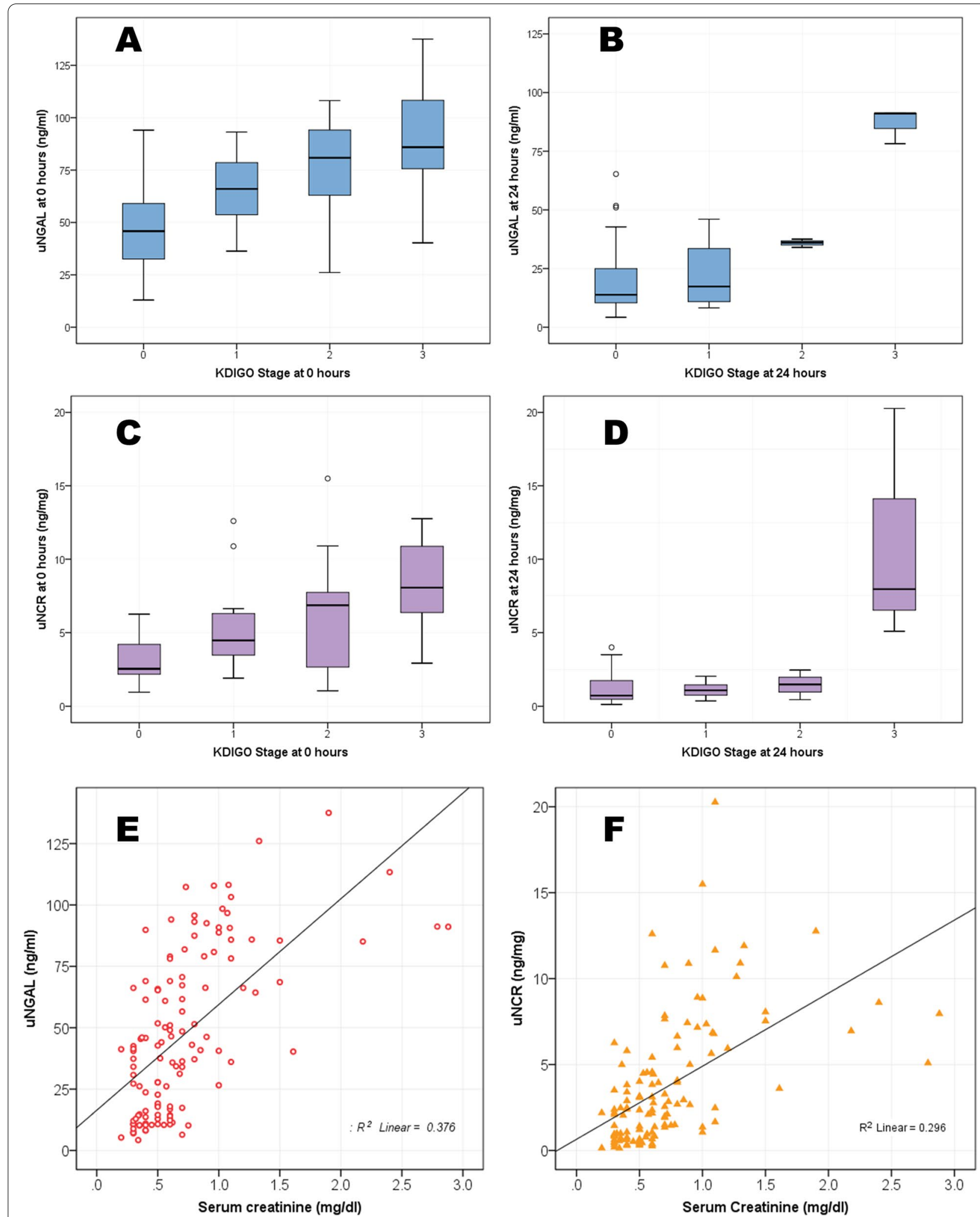

Fig. 1 Panel A and B: Box plot representing UNGAL in relation to KDIGO Stage at 0 and 24h respectively; Panel C and D: Box plot representing UNCR in relation to KDIGO Stage at 0 and $24 \mathrm{~h}$ respectively; Panel $\mathrm{E}$ and $\mathrm{F}$ : Scatter plot representing correlation of UNGAL and UNCR to creatinine 
Table 3 Parameters for predicting persistent AKI at $48 \mathrm{~h}$

\begin{tabular}{|c|c|c|c|c|c|}
\hline Parameter & Value & Sensitivity & Specificity & $\mathrm{AUC}(\mathrm{Cl})$ & $\mathbf{P}$ \\
\hline \multirow[t]{3}{*}{ uNGAL at $0 \mathrm{~h}, \mathrm{ng} / \mathrm{ml}$} & 66.0 & 100 & 48 & $0.78(0.65,0.92)$ & 0.09 \\
\hline & 83.5 & 100 & 69 & & \\
\hline & 88.1 & 66 & 76 & & \\
\hline \multirow[t]{3}{*}{ uNCR at $0 \mathrm{~h}, \mathrm{ng} / \mathrm{mg}$} & 5.9 & 100 & 63 & $0.89(0.75,1.0)$ & 0.02 \\
\hline & 6.9 & 100 & 73 & & \\
\hline & 11.3 & 67 & 95 & & \\
\hline \multirow[t]{2}{*}{ Decline of uNGAL over $24 \mathrm{~h}(\%)$} & 25 & 100 & 95 & $0.97(0.93,1.0)$ & 0.006 \\
\hline & 50 & 100 & 82 & & \\
\hline \multirow[t]{2}{*}{ Decline of uNCR over $24 \mathrm{~h}(\%)$} & 50 & 100 & 93 & $0.98(0.94,1.0)$ & 0.005 \\
\hline & 75 & 100 & 52 & & \\
\hline
\end{tabular}

tuNGAL- urinary Neutrophil gelatinase-associated lipocalin, uNCR- urinary Neutrophil gelatinase-associated lipocalin- Creatinine ratio, AKI- acute kidney injury, AUCArea under curve

from AKI. Kellum et al., analyzed 16,968 critically ill patients to describe 5 distinct patterns of recovery. Early reversal $(n=4508 ; 26.6 \%)$ was the most common, followed by no reversal (4496; $26.5 \%)$, early reversal with one or more relapses, but ultimate recovery (22.5\%), relapsing without recovery (14.7\%), and late reversal after day 7 (9.7\%). Age-adjusted survival at 1 year was $>90 \%$ for early reversal and $<40 \%$ for no reversal [10]. This data reiterates the need for predicting the pattern of AKI resolution so as to target interventions and improve outcome. Transient and persistent AKI have different clinical phenotypes and outcomes. Persistent AKI was associated with worse outcomes irrespective of the degree of severity.

DKA being a state of volume depletion, the occurrence of AKI is common [6]. Adequate and timely fluid replacement mostly reverses AKI. However, in some patients, AKI tends to become intrinsic due to factors such as delayed diagnosis, prolonged uncorrected hypovolemia, severe acidosis and associated sepsis [3, 4, 7]. In such a setting, over-reliance on creatinine to monitor progression or recovery can lead to a false sense of complacency. Large volume resuscitation may decrease creatinine secondary to dilution or increased creatinine filtration [35]. Given these caveats, early detection of progressive AKI calls for a non-creatinine-based marker. This has been emphasized by the ADQI-16 to identify patients at high risk for persistent AKI.

In this context, we believe our findings that show good correlation between uNGAL and uNCR and elevated serum creatinine hold promise. UNGAL and UNCR were discriminative of KDIGO stages both at 0 and $24 \mathrm{~h}$ of admission. The degree of elevation was proportionate to the KGIDO stage of AKI. Such correlation has been consistently reported in other studies as well [36-38]. While interpreting UNGAL values, age-specific variations need to be kept in mind. Infants tend to have a higher uNGAL, which decreases with age. Previously published uNGAL values, range from $1.64(0.25-5.77) \mathrm{ng} / \mathrm{mL}$ in healthy children [39] to 5 (2-150) $\mathrm{ng} / \mathrm{mL}$ in very low birthweight infants [40]. Rybi-Szumińska et al., measured uNCR in 172 healthy children and adolescents and found a similar decreasing trend with age. The median value for 2 months-6years was $4.77(3.06,10.64), 6-10$ years was $2.72(1.14,7.03), 10-14$ years was $1.55(0.43,4.64)$ and $14-18$ years was $0.88(0.16,3.06)$ [41].

To date, the usage of NGAL as a predictor of AKI resolution was limited to very few studies in critically ill patients [28, 29, 42]. Srisawat et al., first described plasma NGAL as a useful biomarker for predicting renal recovery in AKI following community acquired pneumonia [42]. Following this, the BioMaRK study found that a decreasing UNGAL in the first 14 days was associated with greater odds of recovery in critically ill adults [27]. Furthermore, Moon et al., measured uNGAL every alternate day for 8 days in patients with AKI $(n=66)$ to determine AKI recovery which was defined as a $50 \%$ or greater decrease in plasma creatinine from the peak level. They found a good discrimination value for predicting AKI recovery [43]. Nickolas et al., in their single-center study have shown uNGAL to strongly predict sustained AKI with an AUC $>0.90$ [44]. However, Meersch et al., showed contradictory findings; uNGAL in 50 adults postcardiac surgery was a poor predictor for renal recovery at discharge [AUC $(95 \% \mathrm{CI})-0.48(0.31-0.64)]$ [28]. Therefore, we believe that the evidence regarding the ability of uNGAL to differentiate persistent from transient AKI is equivocal.

The clinical settings in the above studies viz. sepsis, post-cardiac surgery in adults are high risk states for persistent AKI. On the contrary, in DKA, AKI mostly resolves. Also, the definitions of persistent AKI were 


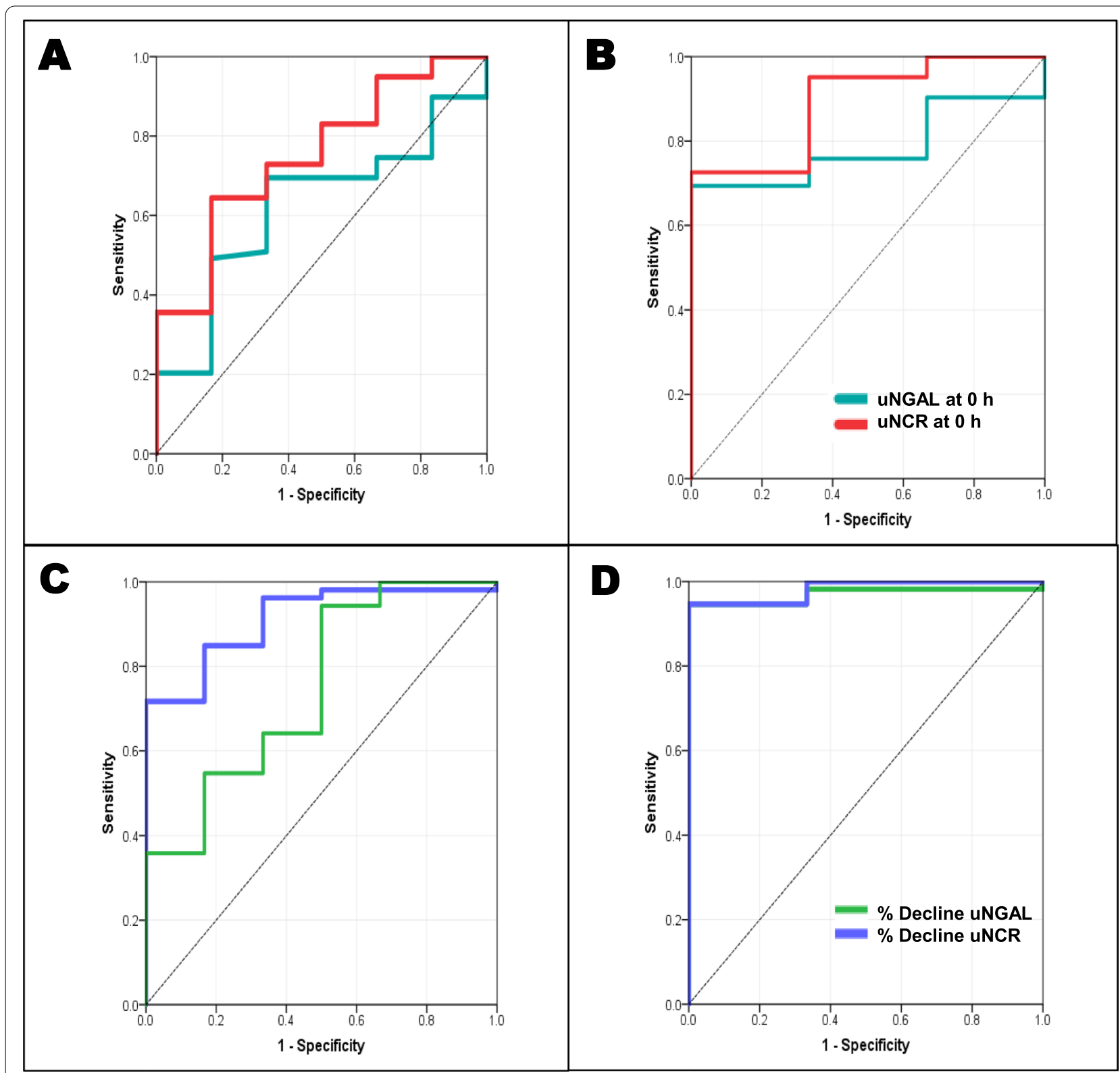

Fig. 2 Panel A and B: ROC showing discriminating ability of UNGAL and UNCR at $0 \mathrm{~h}$ in resolution of AKI at 24 and $48 \mathrm{~h}$ respectively; Panel C and D: ROC showing discriminating ability of \% decline in UNGAL and UNCR at $24 \mathrm{~h}$ in resolution of AKI at 24 and $48 \mathrm{~h}$ respectively

quite variable. In this exploratory study, admission levels of uNGAL, uNCR, and the percentage of decline in both from admission to $24 \mathrm{~h}$ were found to be good predictors of persistent AKI in children with DKA. However, the positive predictive value (PPV) was low and negative predictive value (NPV) was high. Diagnostic accuracy, impact on patient-oriented outcomes and cost are the major determinants for any diagnostic test to be used in clinical practice; merely establishing a diagnosis may not translate to clinical benefit in all cases. Furthermore, given the low incidence of persistent AKI, routine use of uNGAL in a setting where majority of AKI resolves with hydration may be superfluous and not cost effective.

\section{Strengths and limitations}

This is the first study of its kind in DKA that has explored the utility of uNGAL for persistent AKI in children. However, there are important limitations to this study. First of all, it is a post hoc analysis of a single-center study with relatively low sample size. Secondly, the population of 
children with DKA evaluated in this study was younger and more severely ill than is typical in other studies of DKA. Finally, this being a cross sectional analysis, long term risk of progression to CKD and its relation to uNGAL could not be fully explored. Future multicenter prospective studies may confirm the utility of UNGAL as early predictive biomarker for persistent AKI in DKA.

\section{Study implications}

In our study, persistent AKI was characterized by lower decline in uNGAL during serial estimation. This is a novel finding and there are no similar reports in literature. It can help classify AKI in DKA as transient (responders to fluids) and persistent (those who will need additional targeted interventions like fluid titration, drug dose adjustment and RRT). Having said this, we believe that the majority of AKI in DKA is transient and resolves with hydration. The incidence of severe DKA and persistent AKI may be less in developed economies, where healthcare seeking is prompt unlike the developing economies. Despite this difference, recommending serial uNGAL measurement based on our findings may not be cost effective in resource limited settings.. Although both serum and urine NGAL may aid in risk stratification, its utility in prediction models need to be tested further in children.

\section{Conclusion}

AKI at presentation is common in DKA. We found that uNGAL and uNCR had good correlation with serum creatinine and their elevation corresponded to the stage of AKI. While serial uNGAL measurement had good predictive ability for persistent AKI, uNCR performed better than uNGAL alone. Since most AKI resolved with hydration, the utility of UNGAL in predicting persistent AKI needs further evaluation in larger prospective studies.

\section{Supplementary Information}

The online version contains supplementary material available at https://doi. org/10.1186/s40842-021-00133-8.

\section{Additional file 1.}

\section{Acknowledgments}

A special thanks to Dr. Sahul Bharti MBBS, MD, Founder, Build Healthy India Movement (Research based NGO), Chandigarh, India for his valuable statistical inputs in the manuscript. We also thank Dr. Rajalakshmi lyer for her support during the study and in editing the manuscript.

\section{Authors' contribution}

Conception \& design - VW and JM; Preparation of research proposal and protocols; Protocol dissemination; Patient enrolment - VW, JM, KN, DD; Data Collection, analysis \& interpretation - VW, JM, AR, SVA; Drafting and manuscript and reviewing for important intellectual content - All authors.

\section{Availability of data and materials}

The datasets used and/or analyzed during the current study are available from the corresponding author on reasonable request.

\section{Declarations}

Ethical approval and consent to participate

Trial was initiated after approval from the Institute Ethics Committee [Ref. no. NK/3967/DM]. The study was registered with Clinical Trials Registry - India [CTRI/2018/05/014042 (ctri.nic.in)].

\section{Financial support}

This was a secondary analysis of the SPinK trial which was supported by the Indian council of Medical Research (ICMR), as a part of DM dissertation [3/2/ Jan.2017/PG-Thesis-HRD (13).

\section{Consent for publication}

Not applicable.

\section{Competing interests}

The authors declare that they have no competing interests.

\section{Author details}

${ }^{1}$ Division of Pediatric Intensive Care, Department of Critical Care, Sheikh Khalifa Medical City (SKMC), Abu Dhabi, United Arab Emirates. ${ }^{2}$ Division of Pediatric Emergency and Intensive Care, Department of Pediatrics, Advanced Pediatrics Centre, Post Graduate Institute of Medical Education \& Research, Chandigarh, India. ${ }^{3}$ Division of Pediatric Endocrinology, Department of Pediatrics, Advanced Pediatrics Centre, Post Graduate Institute of Medical Education \& Research, Chandigarh, India. ${ }^{4}$ Division of Pediatric Allergy and Immunology, Department of Pediatrics, Advanced Pediatrics Centre, Postgraduate Institute of Medical Education and Research, Chandigarh, India. ${ }^{5}$ Division of Pediatric Biochemistry, Department of Pediatrics, Advanced Pediatrics Centre, Postgraduate Institute of Medical Education and Research, Chandigarh, India.

Received: 27 October 2020 Accepted: 27 September 2021

Published online: 01 November 2021

\section{References}

1. Umpierrez GE, Kitabchi AE. Diabetic Ketoacidosis. Treat Endocrinol. 2003;2(2):95-108.

2. Umpierrez G, Freire AX. Abdominal pain in patients with hyperglycemic crises. J Crit Care. 2002;17(1):63-7. https://doi.org/10.1053/jcrc.2002. 33030 .

3. Moulik NR, Jayashree M, Singhi S, Bhalla AK, Attri S. Nutritional status and complications in children with diabetic ketoacidosis. Pediatr Crit Care Med. 2012;13(4):e227-33. https://doi.org/10.1097/PCC.0b013e3182 3c9a11.

4. Jayashree M, Williams V, lyer R. Fluid therapy for pediatric patients with diabetic ketoacidosis: current perspectives. Diabetes Metab Syndr Obes. 2019:12:2355-61. https://doi.org/10.2147/DMSO.S194944.

5. Williams V, Jaiswal N, Chauhan A, Pradhan P, Jayashree M, Singh M. Time of pediatric intensive care unit admission and mortality: a systematic review and Meta-analysis. Journal of Pediatric Intensive Care Published online November 18, 2019. https://doi.org/10.1055/s-00393399581.

6. Hursh BE, Ronsley R, Islam N, Mammen C, Panagiotopoulos C. Acute kidney injury in children with type 1 diabetes hospitalized for diabetic ketoacidosis. JAMA Pediatr. 2017;171(5):e170020-0. https://doi.org/10. 1001/jamapediatrics.2017.0020.

7. Baalaaji M, Jayashree M, Nallasamy K, Singhi S, Bansal A. Predictors and outcome of acute kidney injury in children with diabetic ketoacidosis. Indian Pediatr. 2018;55(4):311-4.

8. Parajuli B, Kumar Angurana S, Baalaaji M, Williams V. Acute kidney injury in children with diabetic ketoacidosis: a real concern. Pediatr Crit Care Med. 2019:20(6):590-1. https://doi.org/10.1097/PCC.0000000000001928.

9. Weissbach A, Zur N, Kaplan E, Kadmon G, Gendler Y, Nahum E. Acute kidney injury in critically ill children admitted to the PICU for diabetic 
ketoacidosis. A retrospective study. Pediatr Crit Care Med. 2019;20(1):e104. https://doi.org/10.1097/PCC.0000000000001758.

10. Kellum JA, Sileanu FE, Bihorac A, Hoste EAJ, Chawla LS. Recovery after acute kidney injury. Am J Respir Crit Care Med. 2017;195(6):784-91. https://doi.org/10.1164/rccm.201604-07990C

11. Chawla LS, Bellomo R, Bihorac A, et al. Acute kidney disease and renal recovery: consensus report of the acute disease quality initiative (ADQI) 16 workgroup. Nat Rev Nephrol. 2017;13(4):241-57. https://doi.org/10. 1038/nrneph.2017.2.

12. Williams V, Jayashree M, Nallasamy K, Dayal D, Rawat A. 0.9\% saline versus Plasma-Lyte as initial fluid in children with diabetic ketoacidosis (SPinK trial): a double-blind randomized controlled trial. Critical Care. 2020:24(1):1. https://doi.org/10.1186/s13054-019-2683-3.

13. Mehta S, Chauhan K, Patel A, et al. The prognostic importance of duration of AKI: a systematic review and meta-analysis. BMC Nephrol. 2018;19(1):91. https://doi.org/10.1186/s12882-018-0876-7.

14. Thakar CV, Christianson A, Himmelfarb J, Leonard AC. Acute kidney injury episodes and chronic kidney disease risk in diabetes mellitus. Clin J Am Soc Nephrol. 2011;6(11):2567-72. https://doi.org/10.2215/CJN.01120211.

15. Chen J, Zeng $H$, Ouyang $X$, et al. The incidence, risk factors, and long-term outcomes of acute kidney injury in hospitalized diabetic ketoacidosis patients. BMC Nephrol. 2020;21. https://doi.org/10.1186/ s12882-020-1709-z.

16. Kashani K, Rosner MH, Ostermann M. Creatinine: from physiology to clinical application. Eur J Intern Med. 2020;72:9-14. https://doi.org/10.1016/j. ejim.2019.10.025.

17. Mishra J, Dent C, Tarabishi R, et al. Neutrophil gelatinase-associated lipocalin (NGAL) as a biomarker for acute renal injury after cardiac surgery. Lancet. 2005;365(9466):1231-8. https://doi.org/10.1016/S01406736(05)74811-X.

18. Mishra J, Ma Q, Prada A, et al. Identification of neutrophil gelatinaseassociated lipocalin as a novel early urinary biomarker for ischemic renal injury. J Am Soc Nephrol. 2003;14(10):2534-43. https://doi.org/10.1097/ 01.asn.0000088027.54400.c6.

19. Supavekin S, Zhang W, Kucherlapati R, Kaskel FJ, Moore LC, Devarajan P. Differential gene expression following early renal ischemia/reperfusion. Kidney Int. 2003;63(5):1714-24. https://doi.org/10.1046/j.1523-1755.2003. 00928.x.

20. Mori K, Nakao K. Neutrophil gelatinase-associated lipocalin as the realtime indicator of active kidney damage. Kidney Int. 2007;71(10):967-70. https://doi.org/10.1038/sj.ki.5002165.

21. Hirsch $R$, Dent $C$, Pfriem $H$, et al. NGAL is an early predictive biomarker of contrast-induced nephropathy in children. Pediatr Nephrol. 2007;22(12):2089-95. https://doi.org/10.1007/s00467-007-0601-4.

22. Bennett $\mathrm{M}$, Dent $\mathrm{CL}$, Ma Q, et al. Urine NGAL predicts severity of acute kidney injury after cardiac surgery: a prospective study. Clin J Am Soc Nephrol. 2008;3(3):665-73. https://doi.org/10.2215/CJN.04010907.

23. Mcllroy DR, Farkas D, Matto M, Lee HT. Neutrophil gelatinase-associated lipocalin combined with delta serum creatinine provides early risk stratification for adverse outcomes after cardiac surgery: a prospective observational study. Crit Care Med. 2015;43(5):1043-52. https://doi.org/ 10.1097/CCM.0000000000000927.

24. Mishra J, Ma Q, Kelly C, et al. Kidney NGAL is a novel early marker of acute injury following transplantation. Pediatr Nephrol. 2006;21 (6):856-63. https://doi.org/10.1007/s00467-006-0055-0.

25. Niemann CU, Walia A, Waldman J, et al. Acute kidney injury during liver transplantation as determined by neutrophil gelatinase-associated lipocalin. Liver Transpl. 2009;15(12):1852-60. https://doi.org/10.1002/lt. 21938.

26. Wagener G, Minhaz M, Mattis FA, Kim M, Emond JC, Lee HT. Urinary neutrophil gelatinase-associated lipocalin as a marker of acute kidney injury after orthotopic liver transplantation. Nephrol Dial Transplant. 2011;26(5):1717-23. https://doi.org/10.1093/ndt/gfq770.

27. Srisawat $N$, Wen $X$, Lee $M$, et al. Urinary biomarkers and renal recovery in critically ill patients with renal support. Clin J Am Soc Nephrol. 2011:6(8):1815-23. https://doi.org/10.2215/CJN.11261210.

28. Meersch M, Schmidt C, Van Aken H, et al. Urinary TIMP-2 and IGFBP7 as early biomarkers of acute kidney injury and renal recovery following cardiac surgery. PLoS One. 2014;9(3):e93460. https://doi.org/10.1371/ journal.pone.0093460.

29. Zappitelli M, Washburn KK, Arikan AA, et al. Urine neutrophil gelatinaseassociated lipocalin is an early marker of acute kidney injury in critically ill children: a prospective cohort study. Crit Care. 2007;11(4):R84. https://doi. org/10.1186/cc6089.

30. Summary of Recommendation Statements. Kidney Int Suppl (2011). 2012;2(1):8-12. https://doi.org/10.1038/kisup.2012.7

31. Schwartz GJ, Muñoz A, Schneider MF, et al. New equations to estimate GFR in children with CKD. J Am Soc Nephrol. 2009;20(3):629-37. https:// doi.org/10.1681/ASN.2008030287.

32. Uchino S, Bellomo R, Bagshaw SM, Goldsmith D. Transient azotaemia is associated with a high risk of death in hospitalized patients. Nephrol Dial Transplant. 2010;25(6):1833-9. https://doi.org/10.1093/ndt/gfp624.

33. Perinel $\mathrm{S}$, Vincent $\mathrm{F}$, Lautrette $\mathrm{A}$, et al. Transient and persistent acute kidney injury and the risk of hospital mortality in critically ill patients: results of a multicenter cohort study. Crit Care Med. 2015;43(8):e269-75. https:// doi.org/10.1097/CCM.0000000000001077.

34. Wolfsdorf JI. The International Society of Pediatric and Adolescent Diabetes guidelines for management of diabetic ketoacidosis: do the guidelines need to be modified? Pediatr Diabetes. 2014;15(4):277-86. https://doi.org/10.1111/pedi.12154.

35. Udy AA, Baptista JP, Lim NL, et al. Augmented renal clearance in the ICU: results of a multicenter observational study of renal function in critically ill patients with normal plasma creatinine concentrations*. Crit Care Med. 2014;42(3):520-7. https://doi.org/10.1097/CCM.0000000000000029.

36. Bachorzewska-Gajewska H, Malyszko J, Sitniewska E, Malyszko JS, Dobrzycki S. Neutrophil gelatinase-associated lipocalin (NGAL) correlations with cystatin C, serum creatinine and eGFR in patients with normal serum creatinine undergoing coronary angiography. Nephrol Dial Transplant. 2007;22(1):295-6. https://doi.org/10.1093/ndt/gfl408.

37. Nickolas TL, Schmidt-Ott KM, Canetta P, et al. Diagnostic and prognostic stratification in the emergency department using urinary biomarkers of nephron damage. J Am Coll Cardiol. 2012;59(3):246-55. https://doi.org/ 10.1016/j.jacc.2011.10.854.

38. Singer E, Elger A, Elitok S, et al. Urinary neutrophil gelatinase-associated lipocalin distinguishes pre-renal from intrinsic renal failure and predicts outcomes. Kidney Int. 2011;80(4):405-14. https://doi.org/10.1038/ki.2011. 41.

39. Wasilewska A, Taranta-Janusz K, Dębek W, Zoch-Zwierz W, KuroczyckaSaniutycz E. KIM-1 and NGAL: new markers of obstructive nephropathy. Pediatr Nephrol. 2011;26(4):579-86. https://doi.org/10.1007/ s00467-011-1773-5.

40. Huynh TK, Bateman DA, Parravicini E, et al. Reference values of urinary neutrophil gelatinase-associated lipocalin in very low birth weight infants. Pediatr Res. 2009;66(5):528-32. https://doi.org/10.1203/PDR. Ob013e3181baa3dd.

41. Rybi-Szumińska A, Wasilewska A, Litwin M, Kułaga Z, Szumiński M. Paediatric normative data for urine NGAL/creatinine ratio. Acta Paediatr. 2013;102(6):e269-72. https://doi.org/10.1111/apa.12200.

42. Srisawat N, Murugan R, Lee M, et al. Plasma neutrophil gelatinaseassociated lipocalin predicts recovery from acute kidney injury following community-acquired pneumonia. Kidney Int. 2011;80(5):545-52. https:// doi.org/10.1038/ki.2011.160

43. Moon SJ, Park HB, Yoon SY, Lee SC. Urinary biomarkers for early detection of recovery in patients with acute kidney injury. J Korean Med Sci. 2013;28(8):1181-6. https://doi.org/10.3346/jkms.2013.28.8.1181.

44. Nickolas TL, O'Rourke MJ, Yang J, et al. Sensitivity and specificity of a single emergency department measurement of urinary neutrophil gelatinase-associated lipocalin for diagnosing acute kidney injury. Ann Intern Med. 2008;148(11):810-9. https://doi.org/10.7326/0003-4819-14811-200806030-00003.

\section{Publisher's Note}

Springer Nature remains neutral with regard to jurisdictional claims in published maps and institutional affiliations. 